\title{
Targeting Females as Voluntary Non Remunerated Donors in Developing Nations
}

Anyanwu-Yeiya $\mathrm{CC}^{*}$, Sonubi $\mathrm{O}$ and Kotila TR

Department of Haematology, University College Hospital, Ibadan, Nigeria

*Corresponding author: Chinonso C. Anyanwu-Yeiya, Department of Haematology, University College Hospital, PMB 5116, Ibadan, Nigeria, Tel: 2342410088; E-mail: yeiyanonso@gmail.com

Received date: May 05, 2015, Accepted date: July 27, 2015, Publication date: July 31, 2015

Copyright: (c) 2015 Anyanwu-Yeiya CC, et al. This is an open-access article distributed under the terms of the Creative Commons Attribution License, which permits unrestricted use, distribution, and reproduction in any medium, provided the original author and source are credited.

\author{
Abstract \\ Objectives: To assess the level of female participation in blood donation at a blood bank of a developing nation \\ and compare findings with that of other parts of the world.
}

Background: Safe blood is the foundation of good blood transfusion practice and voluntary non remunerated donors (VNRD) are the cornerstone. There is therefore always a quest for VNRDs, in order to boost the blood transfusion service. Safe blood practice is not optimal in many developing nations mostly for lack of VNRDs. Female donors are also rarely blood donors in this setting. It may therefore be productive to target this group as a source of VNRDs.

Methods: A retrospective study of blood donors who have been screened for transfusion transmitted infections was carried out at the University College Hospital, Ibadan, Nigeria. Information was obtained from the donor registry of the blood bank from January 2013 - June 2014.

Results: There were 8,619 donors, of which $90.1 \%$ and $9.9 \%$ were male and female respectively. Family replacement donors accounted for $84.7 \%$ of the donors and $15.3 \%$ were VNRD. Female donors were $7.9 \%$ and $21 \%$ of FRD and VNRD respectively. The odds of a female being a VNRD was higher than for a male, 0.48 vs. 0.16 $(\mathrm{OR}=3,95 \% \mathrm{Cl}=2.56-3.51)$.

Conclusion: Females have more potentials of being voluntary donors than males; they should therefore be targeted in improving blood donation in developing countries. There is also the need to explore reasons why females do not regularly donate in this setting and address such.

Keywords: Female donor; Family replacement donor; Voluntary donor; Safe blood

\section{Introduction}

Human blood is essential to life and millions of lives are saved globally by blood transfusion. Despite this, the provision of timely, safe and adequate quantities of blood and blood products is a major challenge to blood safety. Out of 108 million blood donations collected annually worldwide, less than half is collected in developing countries which have about $80 \%$ of the world's population [1]. In these regions, blood is needed more often to manage pregnancy related complications and severe childhood anaemia, particularly from malaria, malnutrition and haemoglobinopathy. The situation emphasizes the need for a continuous and regular supply of safe blood.This can only be achieved by encouraging regular voluntary, non-remunerated blood donation which should be without distinction against sex, race, language, religion or political beliefs [2]. However, there is inequality between the population of male and female blood donors in some parts of the world, especially in Sub-Saharan Africa. Data shows that globally $30 \%$ of blood donations are given by women (WHO Blood Safety, 2014). Reasons that have been proffered for these gender differences include prevalence of iron deficiency and pernicious anaemia, low body weight among prospective female donors and a higher rate of adverse reactions to blood donation related to body weight (e.g. dizziness, fainting), erroneous beliefs, low level of education and cultural factors among women [2-4]. These can result in deferral at the blood donation centres or to self exclusion by prospective female donors.

The objective of this study is to assess the level of female gender participation in blood donation at the University College Hospital, Ibadan, Nigeria and to compare the findings with results obtained from other parts of Nigeria, Africa and other continents.

\section{Materials and Methods}

This was a retrospective study carried out at the Blood Bank of the University College Hospital (UCH), Ibadan, Nigeria. $\mathrm{UCH}$ is strategically located in Ibadan, the capital city of Oyo State, South Western Nigeria. With a population of 1.3 million people, Ibadan is the third largest metropolitan city after Lagos and Kano, and the largest metropolitan geographical area in Nigeria [5]. UCH, Ibadan currently has 850 bed spaces, an average annual patient turnout of 6,000 at its Accident and Emergency (A and E) Department and about 150,000 new cases go through its various clinics every year.

The subjects for this study were 8,619 people, age range 18-60 years, who donated blood at the blood bank of University College Hospital, 
Ibadan, Nigeria between January 2013 and June 2014. Information was obtained from the donor registry of the blood bank. They (donors) had passed the blood bank's qualification criteria which included an assessment of their medical history and lifestyle; age, weight, $\mathrm{CuSO} 4$ test, and screening for Syphilis, HIV, Hepatitis B and C viruses. Their blood groups (ABO and $\mathrm{Rh}$ ) had also been determined. Donors were categorized according to gender and the type of donation (FRD and VNRD) made. Data collected was entered into excel spreadsheet. Their frequencies were compared and Chi-square test was used to determine if the observed differences were of statistical importance. A p-value of $<0.05$ was chosen to denote a statistically significant difference.

\section{Results}

There were 8,619 donors over the 18 months period, of which 857 $(9.9 \%)$ were female. Majority of the donations (86.7\%) were of the family replacement type. Females made up $7.9 \%$ and $21 \%$ of FRD and VNRDs respectively. Furthermore, the odds of a female (0.48) being a VNRD was found to be three times that of a male donor $(0.16)[\mathrm{OR}=3$, $95 \% \mathrm{CI}=2.56-3.51]$.

\section{Discussion}

This study revealed that few women $(9.9 \%)$ participated in blood donation during the period observed and that female donors have three times the potentials of becoming a voluntary non remunerated donors than males (odds ratio of 3 ). In a similar study done in Sokoto, Nigerian females constituted only $0.6 \%$ of donors [4]. Reports from other parts West Africa show women contributing 10\% in Ghana [6], and up to $28.8 \%$ and $30 \%$ in Burkina Faso [7] and Togo [8] respectively. Iran and India report female participation of $5 \%$ and $10.7 \%$ respectively, whereas the participation rises to $33 \%$ in Italy and Greece [2]. Females account for greater than $40 \%$ of donors in Swaziland and Zimbabwe [9]; 45.5\% of donors in the United States; $50 \%$ in Norway, France, Netherlands; and 55\% in Great Britain and Finland $[4,6,10]$.

Our study also demonstrates that female participation in blood donation at Ibadan, South Western Nigeria is higher than that found in Sokoto, North Western Nigeria and Iran; and comparable to findings in Ghana and India. It however falls short of what is obtainable in neighbouring francophone West African countries like Burkina Faso and Togo, or in other Sub- Saharan Africa countries like Swaziland and Zimbabwe, and in high-income countries such as Great Britain and the United States.

Blood donation in Sub-Saharan Africa is generally affected by prejudices, misconceptions, cultural differences and lack of information. Men are assumed to be healthier than women who loose blood monthly during menstruation. Pregnancy and breastfeeding further deter blood donation by women. In North Western Nigeria, poverty, lack of access to education, unemployment, other socioeconomic factors and religious misinterpretations have been suggested to be factors for the low level of female blood donation observed in the region [4]. The fear of contracting a disease from donation (especially HIV), fear of knowing ones HIV status, and lack of opportunity to donate are among factors identified as barriers to blood donation in Sub-Saharan Africa $[8,11]$.

Education has been found to have a strong influence on attitudes toward blood donation $[12,13]$. Female literacy rate in Nigeria (50.4\%) is higher than in Burkina Faso (21.6\%) and Togo (46.9\%), but lower than that found in Swaziland (87.3\%), Zimbabwe (80.1\%), or The
United Kingdom and United States where female literacy rate is almost $100 \%$, respectively [14]. In the light of this, improved female literacy level in Nigeria may reflect in increased female participation in blood donation process.

Some studies have shown that women have less knowledge concerning blood donation and its criteria compared to men. A study in Yazd, Iran also found that working class women donate more than housewives [10]. The perception of being anaemic was among the major reasons given for not donating. Lack of permission by spouse or family elders, pregnancy and lactation scored the lowest among their reasons for not donating blood. A previous study determined that $55.6 \%$ of prospective first time female donors were found to have iron deficiency anaemia [15].

Various avenues can be manipulated to motivate people, especially women, to donate more. Any strategy must be by socio-culturally and religiously acceptable in the regions where they are employed. A study investigating knowledge and attitudes of blood donors in Jordan revealed that the decision to donate blood was influenced by friends, media, and religion [16]. Similarly, in Saudi Arabia, religion has been found to be a greater motive as blood donation is viewed as a religious duty [17]. These are in contrast to findings in the United States where blood donation campaigns have been found to be more influential than family and/or peers in motivating donation [18].

Our study showed that FRD accounted for $85 \%$ of the total blood donations in University College Hospital, Ibadan, Nigeria. This is an improvement from findings in a 2008 study in the same blood bank where FRDs made up 94\% of the total donors [19]. These observations drastically fall short of WHO vision for $100 \%$ voluntary nonremunerated blood donation in every country of the world by 2020 [9].

A blood bank audit at University College Hospital, Ibadan in 2008 revealed that there was inadequate supply of blood with only $64 \%$ supply made following requests for red cell units [20]. This shortfall emphasizes the need to increase the number of altruistic repeat blood donors and improve blood supply in blood banks. Ingenious means are necessary therefore to encourage more people to participate in the blood donation process.

To encourage female participation in blood donation, measures have to be put in place to combat the myriad causes of poverty, illiteracy, anaemia, underweight and misconceptions among women. These could be done by encouraging female education and their financial empowerment, and improving their access to health care. Furthermore, understanding their ability to influence family members to become donors, women attending antenatal clinics and social/ religious meetings can be targeted for education and encouraged to consider becoming potential blood donors and also recruit other members of the society.

\section{Conclusion}

This study has shown that female donors are appropriate targets for voluntary non remunerated blood donation in Ibadan, South Western Nigeria. It has also highlighted the need to further assess the population's knowledge, attitude and practice to blood donation process, so as to identify the prevailing barriers to female blood donation in the region. Work is currently in progress to investigate the reasons responsible for low female participation in blood donation in Ibadan, Nigeria. 
Citation: Anyanwu-Yeiya CC, Sonubi O, Kotila TR (2015) Targeting Females as Voluntary Non Remunerated Donors in Developing Nations. J Blood Disord Transfus S4: S4-002. doi:10.4172/2155-9864.1000S4-002

Page 3 of 3

\section{References}

1. http://www.who.int/mediacentre/factsheets/fs279/en/.

2. Bani M, Giussani B (2010) Gender differences in giving blood: a review of the literature. Blood Transfus 8: 278-287.

3. Ersan G, Liv F, Köse S2 (2012) Blood donation: survey results. Turk J Haematol 29: 87-88.

4. Erhabor O, Isaac Z, Abdulrahaman Y, Ndakotsu M, Ikhuenbor DB, et al. (2013). Female gender participation in the blood donation process in resource poor settings: case study of Sokoto in North Western Nigeria. J Blood Disorders Transf 5: 176.

5. http://en.m.wikipedia.org/wiki/Ibadan.

6. Allain JP, Sarkodie F, Boateng P, Asenso K, Kyeremateng E, et al. (2008) A pool of repeat blood donors can be generated with little expense to the blood center in sub-Saharan Africa. Transfusion 48: 735-741.

7. Nébié KY, Olinger CM, Kafando E, Dahourou H, Diallo S, et al. (2007) [Lack of knowledge among blood donors in Burkina Faso (West Africa); potential obstacle to transfusion security]. Transfus Clin Biol 14: 446-452.

8. Agbovi KK, Kolou M, Fétéké L, Haudrechy D, North ML, et al. (2006) [Knowledge, attitudes and practices about blood donation. A sociological study among the population of Lomé in Togo]. Transfus Clin Biol 13: 260-265.

9. http://www.who.int/mediacentre/news/releases/2011/ bloodsafety_20110614/en/.

10. Javadzadeh Shahshahani H (2007) Why don't women volunteer to give blood? A study of knowledge, attitude and practice of women about blood donation, Yazd, Iran, 2005. Transfus Med 17: 451-454.

11. Salaudeen AG, Odeh E (2011) Knowledge and behavior towards voluntary blood donation among students of a tertiary institution in Nigeria. Niger J Clin Pract 14: 303-307.
12. Jacobs B, Berege ZA (1995) Attitudes and beliefs about blood donation among adults in Mwanza Region, Tanzania. East Afr Med J 72: 345-348.

13. Olaiya MA, Alakija W, Ajala A, Olatunji RO (2004) Knowledge, attitudes, beliefs and motivations towards blood donations among blood donors in Lagos, Nigeria. Transfus Med 14: 13-17.

14. https://www.cia.gov/library/publications/the-world-factbook/fields/ 2103.html\#xx.

15. Javadzadeh Shahshahani H, Attar M, Taher Yavari M (2005) A study of the prevalence of iron deficiency and its related factors in blood donors of Yazd, Iran, 2003. Transfus Med 15: 287-293.

16. Abderrahman BH, Saleh YN (2014) Investigating knowledge and attitudes of blood donors and barriers concerning blood donation in Jordan. Procedia-Social and Behavioral Science 116: 2146-2154.

17. Alam M, Masalmeh Bel D (2004) Knowledge, attitudes and practices regarding blood donation among the Saudi population. Saudi Med J 25: 318-321.

18. Glynn SA, Kleinman SH, Schreiber GB, Zuck T, Combs SM, et al. (2002) Motivations to donate blood: demographic comparisons. Transfusion 42: 216-225.

19. Kotila TR, Fasola FA (2008) Pattern of blood donation in a Nigerian tertiary hospital: the way forward. Africa Sanguine 11: 19-21.

20. Fasola FA, Kotila TR, Shokunbi WA (2009) Audit of the red cell units supply of a busy hospital blood bank in Nigeria. Niger J Clin Pract 12: 165-168.
This article was originally published in a special issue, entitled: "Rh Blood Group System", Edited by Smita Mahapatra, SCB Medical College \& Hospital, India 